\title{
Ferrovias, nômades e exilados
}

\section{Carlos Roberto Monteiro de Andrade}

Arquiteto e sociólogo, professor doutor do Departamento de Arquitetura e Urbanismo da EESC-USP, Av. Trabalhador Sancarlense, 400, Centro, CEP 13566-590, São Carlos, SP,

(16) 3373-9800, candrade@sc.usp.br

\begin{abstract}
Resumo
Qual a forma de territorialidade do nômade? O que a distingue daquela do exilado? Procurando responder a essas questões, este texto discute as relações do nomadismo com a ferrovia - enfocando a dimensão disciplinar desse meio de transporte -, bem como a presença do nômade e do exilado nas metrópoles contemporâneas, apontando algumas de suas características.
\end{abstract}

Palavras-chave: nomadismo, ferrovia, exilado.

1. Este texto é uma versão modificada da exposição que realizamos em 8 de novembro de 1995, em São Paulo, sobre o tema "Nômades e exilados na cidade", no evento A cidade e o trem, organizado por Nelson Brissac Peixoto.

2. Uma tradução para o português, quase ao pé da letra, seria "Segurando por baixo", mas foi traduzido por "De vagões e vagabundos" em livro com o mesmo título.

Ao surfista ferroviário, não por sua coragem e loucura, mas pelo uso lúdico que faz do trem, subvertendo o uso do vagão em um ato alucinado e irresponsável, que nos mostra os limites a que pode chegar uma juventude de exilados, nômades do capital.

- alar sobre nômades e exilados em um seminário' que tem por tema principal a ferrovia e suas relações com a cidade leva-nos a recordar dois escritores norte-americanos que comentaram o mesmo tema em passagens de suas obras. Seus pontos de vista em relação à ferrovia vão, no entanto, em sentido contrário ao do fetiche que o trem e seu aparato técnico-industrial promovem, chamando nossa atenção para o lado nada poético e profundamente disciplinador do sistema ferroviário.

O primeiro dos autores é Henry David Thoreau (1817-1862), que em seu principal livro - Walden ou A vida nos bosques, publicado em 1854 - prega a volta à natureza, com um discurso radicalmente antitecnicista, posicionando-se claramente contrário ao trem e a tudo que ele começava a representar. Afirma Thoreau: "Não andamos sobre a estrada de ferro, ela é que anda sob nós" (1984, p. 93), indicando pioneiramente o controle que a ferrovia exercerá sobre seus usuários. Ou então, destacando a dimensão disciplinadora da vida cotidiana presente no sistema ferroviário, observa:

"As partidas e chegadas dos trens demarcam o dia da cidadezinha. Eles vão e vêm com tal regularidade e precisão, e o seu apito pode ser ouvido de tão longe, que os lavradores acertam seus relógios por eles, de modo que uma instituição bem dirigida regula o país inteiro" (op. cit., p. 117).

O outro autor é o escritor Jack London (1876-1916), que em um relato denominado Holding her down, ${ }^{2}$ descreve o que faziam os guardas ferroviários para desalojarem os vagabundos que procuravam se segurar sob os vagões blindados (aqueles sem portas nas extremidades) para viajarem clandestinamente. Leiamos um parágrafo de London que resume tal expediente:

"O tira encarregado dos freios pega uma fina barra de aço e um bom pedaço de corda de sino e leva-os até a plataforma em frente do eixo no qual o vagabundo 
3. Ver a respeito: Aurenche (1984) e também National Geographic Society U. S. (1971). está escondido. Amarra a corda de sino na barra e deixa-a pendurada entre a plataforma de dois vagões, esticando um pouco a corda. A barra de aço choca-se contra os dormentes dos trilhos, rebate a toda velocidade contra o fundo do vagão e volta de novo contra os dormentes. O tira balança-a pra frente e pra trás, primeiro de um lado, depois do outro, estendendo um pouco mais a corda aqui recolhendoa um pouco lá, dando à sua arma a oportunidade para toda uma variação de ângulos e impactos. Cada golpe dessa barra voadora vem carregado de morte e a cem quilômetros por hora ela se torna uma verdadeira metralhadora assassina. No dia seguinte os restos do vagabundo são recolhidos à beira da estrada e uma linha nos jornais da cidade menciona o desconhecido, um vagabundo, sem dúvida, embriagado, com certeza, que provavelmente caíra no sono sobre os trilhos" (London, 1985, p. 37).

De Thoreau e London retiremos a inspiração para pensarmos o universo dos nômades e exilados e suas relações com a cidade e o sistema ferroviário. Suas citações delimitam pontos de vista que consideramos radicais em relação à ferrovia, que constituirá a principal rede de controle territorial desenvolvida pelo capital durante mais de um século, desde o segundo quartel do XIX até o fim dos anos 1930. Por outro lado, a questão dos nômades e exilados das cidades e metrópoles contemporâneas talvez permita, fazendo vir à tona um outro lado da ferrovia, tratarmos aqui o fetiche do trem, quando consideramos este meio apenas de um ponto de vista estético. É nesse sentido que procuraremos estabelecer a distinção conceitual entre nômades e exilados, para em seguida procurar estabelecer seus vínculos com os trens e as cidades.

Nômades e nomadismo são conceitos que dizem respeito a uma forma de territorialidade específica, caracterizada pela mobilidade e dispersão geográfica e que se realiza sob o princípio da errância, o que é como bem lembram os situacionistas - totalmente distinto da viagem turística. A viagem para o nômade é o tempo da plenitude de sua territorialidade. Para ele, seu acampamento é sempre provisório, um lugar prestes a ser abandonado. Assim, quanto mais forte o nomadismo de um certo grupo cultural, menor seu tempo de permanência em um acampamento. Tal fato confere apenas aos territórios por onde realiza sua deriva - sejam eles desertos de gelo ou de areia, atravessados por esquimós ou beduínos, ou então florestas ou estepes, percorridos pelos últimos yanomamis ou românis - o espaço peculiar que dá sentido pleno à sua territorialidade. ${ }^{3}$

Desenvolvendo meios específicos de localização no território, os grupos nômades apresentam motivos diversos que promovem a suspensão do repouso, o levantamento do acampamento e o seguir viagem. Se estudos antropológicos de nômades florestais reduziram os motivos do abandono de um acampamento, fundamentalmente, a exigências econômicas, como a escassez de alimentos, o livro de Pierre Clastres sobre os guayakis é revelador da existência no interior de tal grupo de causas as mais diversas e menos previstas - ou racionais, segundo nossos padrões - para o abandono de suas choupanas e a retomada da viagem. Podem ser elas, desde a doença que repentinamente acomete uma criança, ou apenas um certo pressentimento do pajé, ou também a - ainda que rara-pouca disponibilidade de caça (Clastres, 1990).

Recordemos aqui, mais uma vez, Thoreau, em um pequeno trecho de seu diário, um breve ensaio intitulado "Walking", datado de 1862, em que comenta uma das formas de nomadismo. Lemos aí sobre a arte do caminhante e sobre

"quem tem o gênio para sauntering, cuja palavra é magnificamente derivada 'de um povo preguiçoso que andava pelo campo, na ldade Média, esmolando, sob o pretexto de ir à Sainte Terre', isto é, à Terra Santa. (...) Aqueles que nunca foram à Terra Santa em suas caminhadas, como pretendiam, são, de fato, meros preguiçosos e vagabundos; mas são saunterers no bom sentido, como eu assim entendo. Alguns, entretanto, derivam a palavra de sans terre, sem terra ou sem casa, a qual, entretanto, no bom sentido, significará não ter uma casa em particular, mas, do mesmo modo, estar sempre em casa. Este é o segredo do bem-sucedido andarilho(sauntering). Aquele que permanece todo tempo quieto em uma casa pode ser o mais vagabundo de todos; porém o andarilho, no bom sentido, não é mais vagabundo que o rio com seus meandros, que está todo o tempo persistentemente buscando o caminho mais curto para o mar. Mas eu prefiro a primeira, a qual é, de fato, a derivação mais provável. Para todos, caminhar é uma sorte de cruzada, pregada por algum Pedro o Eremita dentro de nós, que nos leva seguir em 
4. Ver sobre o tema o belo livro de Héléne Clastres (1978).
5. Ver a respeito os livros de Stoffels (1977), Caiafa (1985) e Perlonguer (1987).

6. O termo "aparelho de captura" foi utilizado por Deleuze e Guatarri no livro Mil planícies (Mille plateaux, 1980), onde também apresentam seu "Tratado de nomadologia". frente e reconquistar a Terra Santa das mãos dos infiéis" (Thoreau, 1993, p. 49).

Nesse texto Thoreau aponta dois modos pelos quais o nomadismo pode se manifestar, mas também uma de suas ambigüidades, que se manifesta no nomadismo de algumas sociedades florestais. É o caso dos guaranis quando, em "busca da terra sem mal", 4 levam o nomadismo às últimas conseqüências, realizando uma viagem sem paradas. Tal nomadismo absoluto, entretanto, parece negar a própria sociedade, uma vez que, sem acampar, ainda que por pouco tempo, o grupo tende a exaurir suas energias, provocando como que um suicídio coletivo. Na busca da terra sem mal, os guaranis revelam a ambigüidade do ser nômade, que é a exigência de um acampamento ainda que provisório.

Lembremos aqui também os grupos sociais que adotam formas de nomadismo metropolitano, como ciganos roms, circenses, vagabundos (isto é, pessoas que recusam a ideologia do trabalho, preferindo a precariedade de uma vida errante à submissão de seus corpos e espíritos livres) e mendigos (ao menos no sentido original, daqueles que fizeram a opção pela vida de mendicância). Ainda que com outras formas, a adoção de práticas nômades pode estar também presente em certos grupos sociais tipicamente urbanos - como é o caso dos punks com sua deriva pela metrópole ou dos michês realizando a deriva homossexual pelo centro paulistano. ${ }^{5}$

Outros modos de nomadismo poderiam ser as práticas de deambulação que, desde a Idade Média, como lembrou Thoreau, fizeram da viagem uma alternativa à regularidade da vida cotidiana protegida pelas muralhas de uma cidade. $\mathrm{Na}$ construção de uma paisagem rural pelos paisagistas ingleses, com sua tradição rústica de jardinagem e suas teorias do pinturesco - de Gainsborough a Ruskin - também vai se manifestar um nomadismo poético e estético dos tours de artistas, que resiste até o início do século XX. A apologia que Patrick Geddes faz da viagem como meio pedagógico inscreve-se nessa tradição, que tem sua origem no grand tour dos membros da compagnonnage.

Por outro lado, a territorialidade nômade opõe-se à territorialidade sedentária, cujos princípios de fixação e concentração espacial, mas também de confina- mento e esquadrinhamento, promovem a urbanização do território, isto é, a criação de uma rede de cidades interligadas por meios de comunicação. É nesse sentido que não é possível concebermos uma cidade fora de uma rede de núcleos urbanos hierarquizados, pois uma cidade isolada é uma cidade morta.

A dimensão disciplinadora da vida cotidiana presente no sistema ferroviário se imporá sobre o território por meio da construção de redes, cuja noção, como apontou Dupuy (1991), é fundamental para o entendimento da cidade moderna e contemporânea. Esta só pode ser pensada como nó de uma rede - a rede urbana-que esquadrinha o território físico-geográfico, configurando-o como um aparelho de captura de fluxos os mais diversos - de homens, mercadorias, idéias e desejos. ${ }^{6}$ Mas é preciso também lembrar que até mesmo a estrutura interna das cidades é marcada pela noção de rede. Assim, temos redes de saneamento, redes viárias, redes de comunicação e de distribuição de energia, redes hospitalares, etc., indicando a forma peculiar que o mundo urbano - em especial a partir do modo de produção capitalista organiza seus serviços e equipamentos de uso coletivo. Para o controle de fluxos nômades, o Estado criará uma ampla rede urbana, que no século XIX se difundiu por territórios ainda inexplorados dos diversos continentes, sobretudo por intermédio das ferrovias.

Vejamos agora as noções de exilados e exílio. Elas remetem a desterro, degredo, expatriação, termos que significam a perda de toda e qualquer territorialidade. É assim que distinguiremos aqui os nômades dos exilados na cidade, embora no que se refira aos modos de sobrevivência de cada um desses grupos encontraremos inúmeras semelhanças. Entretanto, o verdadeiro nômade não reclama qualquer direito de cidadania, já que a cidade é para ele apenas local de passagem, locus transitório em cujos interstícios pode encontrar abrigo provisório e de cujas sobras é possível extrair algum alimento. Por ter cultura própria, que se opõe radicalmente à cultura urbana, o nômade verá a cidade apenas como fonte de algum benefício a ser aproveitado, mas jamais como um direito que lhe está sendo negado. No caso das sociedades "primitivas", se aceitamos a formulação de Pierre Clastres (1990) de que são sociedades contra o Estado, podemos afirmar que o nomadismo é uma das formas de sociabilidade inventada por tais sociedades para impedir o 
7. Lembro que esse texto foi escrito em 1995. aparecimento do Estado, enquanto a cidade é o modo peculiar de o Estado se manifestar no território. Sociedades contra o Estado, os caçadores nômades da floresta são também sociedades contra o urbano.

Já o exilado é aquele que perdeu sua cidadania e se ressente dessa falta, clamando pelo território do qual foi expulso. Desse modo, seus acampamentos não constituem uma forma de territorialidade alternativa, embora possam vir a recriar espaços autônomos que resgatam o sentido originário da rua e da praça. Reproduzem, apesar da precariedade e mobilidade de seus abrigos, o traçado sedentário, adotando quase sempre um desenho que reafirma o esquema urbano tradicional.

As metrópoles contemporâneas deste fim de século7 têm assistido ao desaparecimento da figura do nômade e ao crescimento do número de exilados. Como aparelho de captura que se distribui pelo território, formatando-o com uma arquitetura disciplinar, as redes urbanas - que hoje assistem à expansão do controle também sobre o tempo, como mostrou Virilio - organizam os movimentos. Assim, entre nômades e sedentários vão se estabelecer relações de conflito, de disputa por território, mas também de assimilação. O sistema ferroviário, como momento e parte do complexo de meios de circulação que estruturam o território, reúne em si a contradição entre esses dois modos de habitar (no sentido que Heidegger dá a esse verbo: ser, estar no mundo) - o do nômade e o do sedentário. Se, por um lado, permite novos modos de nomadismo, por outro, constrange os percursos a seus trilhos, seus acampamentos a cercas e seus indivíduos a números em carteiras de identidade.

Desse modo, para o nômade o trem é apenas o meio provisório e descartável para realizar sua mobilidade; nem mesmo é o meio mais adequado, já que o rumo seguro e impositivo que toma a locomotiva, com seu destino preciso, contraria os princípios de errância. Pelo mesmo motivo, como passageiro clandestino, o nômade não espera pela parada na estação e salta antes, para evitar o controle que se exerce naquele espaço. Para o exilado que tem sua territorialidade destruída por intermédio de uma deriva absoluta, o trem é o meio de transporte no qual ele é obrigado a embarcar. E aqui não me refiro apenas aos trens da morte levando prisioneiros para campos de concentração e extermínio, mas a um fato que se reitera em inúmeras cidades, com a expulsão de migrantes que, tal qual os dementes das "naus dos insensatos", vagam sem rumo de uma estação para outra. Flagelados da seca, da fome ou da guerra, exilados, "nomadizam" sem serem propriamente nômades, mas por nada possuírem e por imposição do Estado, em um processo de desenraizamento forçado, perda da terra e da casa, portanto, perda do direito à vida.

Anexemos a esses comentários sobre as relações entre a ferrovia, os nômades e os exilados aqueles feitos por outro autor do século XIX que discute tais temas, ainda que de passagem. Trata-se de Karl Marx em O capital, em um subitem anexo ao capítulo que trata da lei geral da acumulação capitalista, intitulado "A população nômade. Os mineiros". O que o velho Marx nos diz?

"Os nômades do proletariado são recrutados nos campos, mas suas ocupações são em grande parte industriais. É a infantaria ligeira do capital enviada, conforme as necessidades do momento, ora sobre um ponto do país, ora sobre outro. Quando não marcha, ela acampa. Se a emprega na construção, em obras de drenagem, na fabricação de tijolos, no preparo da cal, na construção de estradas de ferro etc. Colônia móvel da pestilência, ela semeia sobre seu caminho, nos locais e entornos de seus assentamentos, a varíola, o tifo, o cólera, a febre escarlatina etc. Quando empresas, tais como as que constroem ferrovias etc., exigem um forte adiantamento de capital, é geralmente o empreendedor quem fornece a seu exército barracas ou alojamentos de madeira, aldeias improvisadas sem nenhuma medida de salubridade, fora da vigilância das autoridades locais, mas fonte de bons lucros para o senhor empresário, que explora seus operários, tanto como soldados da indústria, quanto como inquilinos" (Marx, 1965, p. 1.353).

A longa citação de Marx, que prossegue descrevendo outros exemplos de insalubridade das condições de moradia com suas conseqüências sobre a saúde dos trabalhadores e suas famílias, aponta para uma forma peculiar de nomadismo imposta pelo capital a certas categorias de trabalhadores, como mineiros, construtores de ferrovias ou grandes obras públicas. 
Observando que "o empresário trata toda a colônia como se, ao invés de residir, ela apenas acampasse" (op. cit., p. 1.355), Marx deixa claro que as condições de trabalho e alojamento desses operários são aquelas em que o grau de exploração de sua força é um dos mais intensos e se exerce sobre o trabaIhador também como inquilino. Nômades do capital, ou sua "infantaria ligeira", vagueiam de um lugar para outro em busca de trabalho e, quando o encontram, sua habitação é sempre precária e sobretudo transitória. Nômades do proletariado, são eles também exilados, tocados de canteiro em canteiro. No Brasil dos dias de hoje os nômades do capital são também os bóias-frias cortadores dos canaviais das grandes usinas, ou os garimpeiros da Amazônia, como o foram décadas atrás os candangos que ergueram Brasília ou os barrageiros que construíram as grandes represas e suas usinas elétricas no período do "milagre econômico brasileiro".

Se exiladas são aquelas populações expulsas de sua terra por motivos econômicos, políticos, religiosos ou étnicos, os sem-casa e sem-terra, migrantes, meninos e meninas de rua, moradores dos baixos das pontes e viadutos, também são exilados os prisioneiros de instituições disciplinares como as prisões, campos de concentração, reformatórios e manicômios, onde o confinamento é seu modo de habitar. Nesses espaços carcerários o sedentarismo manifesta-se de modo quase absoluto, conforme a tradição das celas monacais, das quais a solitária é a expressão arquitetônica limite.

Na cidade moderna, à plena exposição que as praças promovem, sobretudo aquelas que serão reformadas ou criadas a partir do Renascimento, corresponde a construção de espaços sob o signo da privacidade, a adoção de estratégias de confinamento e reclusão que, do ponto de vista da arquitetura da cidade, irão se associar à especialização cada vez maior dos edifícios. Talvez nesse sentido possamos pensar os espaços de confinamento - das prisões às escolas como a contrapartida do eclipse dos lugares públicos.

Mas também encontramos outra categoria de exilados nas metrópoles contemporâneas. Aquela dos que se auto-exilam, como os que freqüentam shoppings centers - usinas de uma sociabilidade confinada e artificializada em uma arquitetura sintética -, ou os que habitam condomínios fechados ou casas amuralhadas com grades e guaritas, à maneira dos presídios. Para muitos, é claro, o autoexílio é imposto. Pensar a cidade talvez não seja possível sem concebermos sua muralha, mesmo quando esta é invisível. De qualquer modo, a concepção de enclaves na cidade já está presente nos primeiros subúrbios-jardins erguidos na Inglaterra com muros e portões delimitando as fronteiras de um modo de vida comunitário, que pretendia ser uma alternativa à metrópole, como Hampstead, próximo a Londres, construído em 1907.

As metrópoles e grandes cidades contemporâneas são atravessadas por fluxos diversos, que se ampliam progressivamente em decorrência da expansão dos novos meios tecnológicos de comunicação e transporte. Em especial o fluxo de idéias nunca alcançou velocidades de intercâmbio e difusão tão grandes como nos dias de hoje. Os nômades também navegam por essas ondas, incorporando as novas ferramentas segundo seus interesses. Como fizeram com os trens, fazem hoje via internet, a última rede construída pelo capital. Se aos nômades nada mais resta que as últimas formas de uma cultura exilada, aos exilados sobra apenas a luta pelo direito à cidade, e para ambos a esperança de uma cidade sem muralhas, de estações sem catracas e composições sem fiscais.

\section{Referências bibliográficas}

AURENCHE, Olivier. Nomades et sédentaires. Paris: Ponts et Chaussées, 1984.

CAIAFA, Janice. Movimento punk na cidade. A invasão dos bandos sub. Rio de Janeiro: Jorge Zahar Editor, 1985.

CLASTRES, Héléne. Terra sem mal. São Paulo: Editora Brasiliense, 1978.

CLASTRES, Pierre. A Sociedade contra o Estado. Rio de Janeiro: Editora Livraria Francisco Alves, 1990.

Crônica dos índios guayaki: o que sabem os aché, caçadores nômades do Paraguai. Rio de Janeiro: Editora 34, 1995. 
Deleuze, Gille; GUATARRI, Félix. Mille Plateaux. Paris: Éditions de Minuit, 1980.

DUPUY, Gabriel. L'Urbanisme des réseaux: théories et méthodes. Paris: Éditions Armand Colin, 1991.

LONDON, Jack. De vagões e vagabundos. Porto Alegre: LPM Editores, 1985.

MARX, Karl. Oeuvres, Économie. Paris: Éditions Gallimard, vol. 1, 1965.

NATIONAL GEOGRAPHIC SOCIETY U. S. Nomads of the world. Washington, 1971
PERLONGUER, Néstor. O negócio do michê, a prostituição viril. São Paulo: Editora Brasiliense, 1987.

STOFFELS, Marie-Ghislaine. Os mendigos na cidade de São Paulo. São Paulo: Editora Paz e Terra, 1977.

THOREAU, Henry D. Walden ou a vida nos bosques. São Paulo: Global Editora, 1984.

Walking. In: Civil desobedience and other essays. Nova York: Dover Publications, Inc., 1993. p. 49-74. 


\section{Ferrovias, nômades e exilados}

\section{Carlos Roberto Monteiro de Andrade}

\section{Abstract}

What is theform of nomads territoriality? What distinguishes it from that of the exile? In searching for the answers to these questions, the paper discusses the interrelations between nomadism and the railway. This highlights the disciplinary dimension of this mean of transport which characterizes, among other features, the nomad's and exile's presence in the contemporary metropolis.

Key words: nomadism, raiway, exiled. 